\title{
A Laboratory Based, Problem Solving Pedagogy Prepares Engineering Tech- nology Graduates to Succeed on the Job
}

Dr. John Marshall, University of Southern Maine

John Marshall received his Ph.D. from Texas A\&M University and is the departmental Internship Coordinator at the University of Southern Maine. His areas of specialization include Power and Energy

Processing, Applied Process Control Engineering, Applied Automation Engineering, Fluid Power, and Facility Planning. 


\title{
A Laboratory Based, Problem Solving Pedagogy Prepares Engineering Technology Graduates To Succeed on the Job
}

\begin{abstract}
Our advancing world of computer integration, process control, industrial automation, and telecommunications requires technical problem solvers and knowledgeable decision makers. "The activities of problem solving and decision making are closely intertwined", 1 and both skills can effective be learned through project based capstone courses. The lab based problem solving environment is organized into clusters. These clusters are equipped with components such as computers, printers, programmable logic controllers, sensors, pneumatic valves and actuators, mechanisms, rotary index tables, hydraulic cylinders, electric motors, and vibratory feeder bowls. Participants are grouped into teams that solve realistic industrial problems such as parts sorting, quality control, clamp and work circuits, material handling, and component assembly. Students find this capstone level lab based course both challenging and rewarding as they are required to integrate subject matter learned from many courses throughout their entire degree program.
\end{abstract}

\section{Introduction}

This well developed course integrates competences mastered in other courses such as computer-assisted design, spreadsheet and database utilization, material processing, computer programming, and ergonomics. Students actually use every lab in the building (CAD lab, materials lab, welding lab, etc.) but the focal point is the complex yet inviting industrial problem solving lab. This unique project based course continually challenges the student to advance, grow, internalize and demonstrate the new knowledge and techniques they are leaning.

The goal of this manuscript is to provide participants with insight into a "lab based problem solving learning environment" that was created with industrial partnering and relative few additional dollars. The discussion also identifies how the "need" for this type of project based curriculum became obvious. Accomplishments and outcomes from the student perspective, the University perspective, and the industry perspective are also be shared.

Four prerequisite courses are briefly described before focusing on the lab based, problem solving capstone course. These four courses provide the students with the technical skill sets needed to succeed in the senior level capstone course. 


\section{Freshmen level}

The freshmen level courses that utilize the problem solving learning environment are electricity/electronics and mechanical power conversions. The first course focuses on electrical components and concepts. Students learn how to mathematically calculate electrical variables such as current, voltage, and resistance. Then they physically assemble circuits and test their mathematical results with electronic instrumentation. In another activity, students calculate the frequency needed to drive an electric motor at a several differed speeds (RPM). The students then program a variable speed drive unit and use a strobe light to determine if their calculations were correct.

In the mechanical power conversion curriculum, students gain insight into components such as bearings, gears, chain drives, motors, lubrication, and vibration analysis. The learning lab provides hands-on problem solving activities in each of these areas. The purchase of specialized mechanical power transmission learning modules were subsidized by local industries who realized the need for engineers and technical managers with problem solving abilities.

\section{Sophomore level}

The sophomore level fluid power course also makes extensive use of the facility. This course provides an in-depth investigation into hydraulics and pneumatics systems. Beginning at the system level, students gain an understanding of how the major components function together to make the system work properly. After the big picture is understood, the focus changes to the specific components such as pumps, compressors, manual and solenoid activated directional control valves, pressure and flow control valves, cylinders, motors and conditioners.

Industrial partnering has equipped the learning environment with two state-of-the-art hydraulic trainers where students work with all of these components. The pneumatic modules were a project based assignment designed and fabricated by another class from donated components. Learning is greatly enhanced in this fluid power course from the touch, the sound, and the motion of the actual components being studied.

\section{Junior level}

The junior level process control course utilizes Allen-Bradley programmable logic controllers (PLC) and the accompanying RSLogix software. A dozen clusters are utilized for the hands-on problem solving component of this course. Each cluster is composed of a desktop computer linked to a Micrologix 1000 PLC module which was also designed and fabricated as a project in another class. An organized kit includes typical industrial inputs such push button switches, limit switches, and both inductive and capacitive proximity devices. The kit also includes typical industrial outputs including lights, buzzers, motors, and solenoid activated pneumatic directional control valves. 
Students are given a project assignment in the form of an equipment operation specification. This "problem statement" identifies exactly the sequence of events that must occur and what inputs/outputs (I/O) are specified. From this problem statement, each student develops their own software solution via the scientific problem solving method. Compiling, downloading, wiring I/O and testing their solution takes only a few minutes. This quick feedback is crucial to the learn process. If the program does not work properly, they can modify it and try their new solution without consuming excessive lab time.

Typical process control projects include a traffic intersection where the traffic lights and pedestrian walk signs are accurately sequenced. Another programming and I/O project is a parking garage that tracks vehicles entering and existing, and illuminates either a "Lot Full" or a "Room Available" sign based on the garage's capacity. One of the more challenging problem solving PLC based projects is to develop the logic for a pneumatically powered press. In this safety related scenario, both hands must push separate buttons before the press is allowed to close. The tricky aspect is that if the press operator tapes or ties down one of the buttons, the press will not respond! A small pneumatic cylinder controlled by a solenoid directional control valve simulates the press motions. A total of twelve problem solving projects are utilized in this course.

The PLC modules and I/O devices used in this junior level course were specified at the same voltage and have been designed for patch-cord assembly. This allows the students to focus on the job of learning the software and interfacing the I/O devices without the danger of injuring themselves or the components. In the capstone course, this safety net is not present and more time is spent on these concepts.

\section{Senior level}

Armed with the knowledge and abilities in the prerequisite courses discussed above, students embark on a truly challenging project based problem solving adventure. The senior level capstone course is entitled Applied Automation Engineering. Students find this course both demanding and rewarding as they are required to integrate subject matter learned from many courses throughout their entire degree program.

As mentioned above, students also rely on content they learned from many other courses such as computer-assisted design, rapid prototyping, spreadsheet and database utilization, material processing, computer programming, and ergonomics. Students frequently use every lab in the building (CAD lab, welding lab, etc.) but the focal point is the complex yet inviting industrial problem solving lab. In this project based course, participants are grouped into teams that solve actual industrial problems such as parts sorting, quality control, clamp and work circuits, material handling, and component assembly. 
This past semester a local company provided a suggestion that became the focal point of a student group project. This company prepares a processed chicken product that is sold nationally. It appeared that one of their suppliers used metal staples to seal cardboard boxes and somehow one of the staples ended up in a food product that resulted in litigation. They ask if we could develop a machine that could monitor a line of food products for metallic objects. If metal was found, that product would be physically ejected without slowing down the packaging line.

A four student team designed and fabricated a machine that used proximity sensors and pneumatic cylinders to accomplish this goal. They used golf balls instead of chicken products. Some of the golf balls were coated with aluminum foil to simulate a contaminated product. Of course this machine was not going to be used by the company on the packaging line. But it did serve as a proof-of-concept prototype for one that was professional built and installed by the company.

Another student group used a suggestion from a metal casting company that would check components for proper dimensioning and sort out the rejects. This project based problem solving course is very encompassing, time consuming, and rewarding. It continually challenges the students to advance, grow, internalize and demonstrate the new knowledge and techniques they are learning.

\section{The Need}

Why require project based and/or problem solving courses? Technology is no longer something limited to a few individuals; it is an integral part of everyone's life. As technology advances, employers are seeking a more technically literate population. While industries once competed against their neighbors, now our competitors are other countries that can produce quality goods and products at far lower cost.

Traditional approaches and strategies that worked in the past are not the panacea for the future. "Facts and knowledge can only go so far. Tough problem solving requires the ability to define the true problem, analyze the possible causes, create options, select the most feasible option, and then implement it". ${ }^{2}$ Industries need problem solvers, they need team players, and they need innovative minds. This may only be achievable through progressive curriculums and effective partnerships between industries, universities, and government institutions. Those partners that make the best investment in technically competent employees are going to be those that prosper in the 21 st century.

In conjunction with lecturing and testing, it is important to engage students and challenge them in a creative problem-solving manner that fosters their individual growth and development. As the theoretical knowledge is internalized, students become intrinsically motivated search engines to fuel their own intellectual growth. To effectively connect with students at this level and prepare them for the future we need real-world skills and experiences. 
In order to modernize our program, we need to focus on both the curriculum and the facilities. Strong industrial support in the form of money, equipment, and advice enabled significant facility upgrades. Substantial amounts of faculty time and effort were also required for curriculum revisions. Historically lecture and theory based courses, have been dramatically upgraded to reflect the concepts and skill sets need by today's graduates.

\section{Outcomes}

University administrators routinely visit the project based problem solving learning environment with distinguished guests to highlight the innovative learning approach. The facility has also assisted in topic development for faculty grant writing. All of the courses that utilize the facility are full and students genuinely look forward to each class.

In fact, students become so enthralled in the problem solving process they lose track of time. Local industries frequently suggest the senior capstone projects as a manner to help them solve some of their prototyping issues. An additional outcome has been a continuous supply of companies willing to serve as "hosting firms" for our internship program.

\section{Conclusion}

Skillful teaching technique must be coupled with careful preparation and a thorough understanding of the subject matter in order to produce an open, dynamic environment that will foster problem solving and effective learning.

In addition to reading and calculating, have students analyze, engage actively in class, and apply their learning in both a laboratory environment and in industrial-based internships. Global competitiveness will require that graduates be both analytically proficiency problem solvers, team players, and technically literate.

Just as the task of learning is an individual process, the role of an educator is a multifaceted occupation, and for those in engineering and technology, the challenge is even greater. Few occupations are as essential to the advancement of a technical society as that of an educator. It is through quality education that we prepare individuals for the challenges of today and those of tomorrow.

\section{Bibliography}

1. Free Management Library, Problem Solving, downloaded on February 19, 2007 from http://www.managementhelp.org/prsn_prd/prob_slv.htm.

2. Softskills Courseware, Problem Solving and Decision Making, downloaded on February 19, 2007 from http:// www.softskillscourseware.com/human_resources training/problem solving decision_making.asp. 